\title{
Effect of the Apolipoprotein E $\varepsilon 4$ Allele on the Efficacy and Tolerability of Galantamine in the Treatment of Alzheimer's Disease
}

\author{
Guk-Hee Suh ${ }^{a, b}$ Hee Yeon Jung ${ }^{c}$ Chang Uk Lee ${ }^{d}$ Byoung Hoon Oh ${ }^{e}$ \\ Sang-Kyu Lee ${ }^{b}$ NamJin Lee ${ }^{f}$ JaeHyun Kim ${ }^{g}$ Baik Seok Kee ${ }^{\mathrm{h}}$ Daekwan Ko $^{\mathrm{i}}$ \\ Young-Hoon Kim ${ }^{j}$ Young-Su Ju ${ }^{b}$ InJa Hong ${ }^{k}$ Sungku Choik \\ for the Korean Galantamine Study Group \\ ${ }^{a}$ Division of Neuroscience and Psychological Medicine, Imperial College, School of Medicine, and West \\ London Mental Health NHS, London, UK; ${ }^{b}$ Department of Psychiatry, Hallym University College of Medicine, \\ ${ }^{\mathrm{c}}$ Department of Psychiatry, Seoul National University College of Medicine, ${ }^{\mathrm{d}}$ Department of Psychiatry, \\ The Catholic University of Korea College of Medicine, ${ }^{e}$ Department of Psychiatry, Yonsei University College of \\ Medicine, Seoul, ${ }^{f}$ Chonju Welfare Hospital for the Elderly, Chonju, ${ }^{9}$ Department of Psychiatry, Wonkwang \\ University College of Medicine, Iksan, h Department of Psychiatry, Chung-Ang University College of Medicine, \\ 'Department of Psychiatry, Inje University College of Medicine, Seoul, 'ंPaik Institute for Clinical Research, \\ InJe University, Busan, and ${ }^{\mathrm{k}}$ Janssen Korea Pharmaceutical, Seoul, Korea
}

\section{Key Words}

ApoE $\cdot \varepsilon 4$ allele $\cdot$ Genotype $\cdot$ Galantamine $\cdot$ Weight loss · Psychosis · Alzheimer's disease · Cognition · Function $\cdot$ Behavior

\begin{abstract}
Objective: To investigate the effect of the apolipoprotein $\mathrm{E}(\mathrm{ApoE}) \varepsilon 4$ allele on the efficacy and tolerability of galantamine treatment. Methods: A total of 202 patients with mild to moderate Alzheimer's disease participated in a 16-week, prospective, multi-center, randomized, doubleblind galantamine trial in a Korean population. Patients were assessed at baseline and after 4, 8 and 16 weeks of randomized treatment using the 11-item cognitive subscale of the Alzheimer's Disease Assessment Scale (ADAS-cog/11), the Clinician's Interview-Based Impression of Change plus Caregiver Input (CIBIC-plus), the Disability Assessment for Dementia Scale (DAD), the Behavioural Pathology in Alzheimer's Disease Rating Scale
\end{abstract}

(BEHAVE-AD) and adverse events. ApoE genotypes were determined for all subjects. Results: Of the 202 subjects, 115 carried at least one ApoE $\varepsilon 4$ allele and 87 did not. In both ApoE $\varepsilon 4$ carriers and ApoE $\varepsilon 4$ noncarriers, significant improvements were detected relative to baseline on ADAS-cog/11, CIBIC-plus, DAD and BEHAVE-AD. ApoE $\varepsilon 4$ noncarriers showed better improvement in mean total BEHAVE-AD score and mean psychosis (delusions and hallucinations) subscale score than $A p o E ~ \varepsilon 4$ carriers. The incidence of weight loss was significantly higher in ApoE $\varepsilon 4$ carriers $(\mathrm{n}=11 ; 9.6 \%$ ) than in ApoE $\varepsilon 4$ noncarriers ( $n=1 ; 1.2 \%$ ) during this 16 -week study, even though $92 \%$ of patients who complained of weight loss completed this 16-week trial successfully. Conclusion: ApoE $\varepsilon 4$ genotype does not affect galantamine-related improvements in cognition, global rating, function and behavior. Longer prospective studies with larger patient populations are required to confirm these new findings.

Copyright (c) 2006 S. Karger AG, Basel

\section{KARGER}

Fax +4161306 1234 E-Mailkarger@karger.ch www.karger.com (c) 2006 S. Karger AG, Basel

$1420-8008 / 06 / 0211-0033 \$ 23.50 / 0$

Accessible online at:

www.karger.com/dem
Prof. Guk-Hee Suh

Department of Psychiatry, Hallym University Medical Center

Hangang Sacred Heart Hospital, 94-200 Yungdungpo-Dong

Seoul, 150-030 (Korea)

Tel. +82 22633 5910, Fax +82 22677 9095, E-Mail suhgh@chol.com 


\section{Introduction}

The association between sporadic Alzheimer's disease (AD) and the apolipoprotein E (ApoE) $\varepsilon 4$ allele has extensively been studied and confirmed by many investigators [1]. Neuropathological studies of patients with AD suggest that the presence of the $\mathrm{ApoE} \varepsilon 4$ allele is associated with decreased numbers of cholinergic markers in the temporal cortex and hippocampus [2]. The use of acetylcholinesterase inhibitors (AChEIs), the most widely used antidementia drugs, is based on the cholinergic theory of $\mathrm{AD}$; namely, that the cholinergic deficit is strongly linked to the symptoms and neuropathology of $\mathrm{AD}$, so that replacement, increased availability or decreased degradation of acetylcholine should improve symptoms and could delay progression [3]. Reports about the effect of the ApoE $\varepsilon 4$ allele on response to AChEIs treatment are not consistent. Some investigators reported that the ApoE $\varepsilon 4$ allele had a negative effect on the response to AChEIs, whereas others did not $[2,4]$.

This post-hoc analysis investigates the relationship between the presence of the ApoE $\varepsilon 4$ allele and the response to galantamine treatment including change in cognition, global rating, function, behavior and incidence of adverse events (AEs).

\section{Methods}

\section{Study Design}

Data for these analyses were derived from a 16-week, prospective, multi-center, randomized, double-blind, parallel-group study in patients with mild to moderate $\mathrm{AD}$. The rationale, methods and results of this trial have been described elsewhere [5]. In this trial, we used the recommended 4-week escalation scheme with three arms of galantamine $(8,16,24 \mathrm{mg} /$ day). Patients were assessed at baseline (week 0 ) and after 4,8 and 16 weeks of randomized treatment.

\section{Patients}

Inclusion criteria were as follows: a clinical diagnosis of probable AD, according to the Diagnostic and Statistical Manual of Mental Disorders, Fourth Edition (DSM-IV) [6] and the criteria of the National Institute of Neurological and Communicative Disorders and Stroke and the Alzheimer's Disease and Related Disorders Association [7], age over 50 years old at baseline, presence of mild to moderate dementia (a score of 10-22 on the Mini-Mental State Examination, MMSE [8]; a score of $\geq 14$ on the 11-item cognitive subscale of the AD Assessment Scale, ADAS-cog/11 [9]), a history of cognitive decline with a gradual onset of symptoms and progression over 6 months or more before the study; having responsible caregivers who would be able to provide necessary information about the patient, and giving informed written consent to this genetic study. Patients were excluded if they had evidence of any neurodegenerative disorder other than $\mathrm{AD}$, primary dementia of vascular origin and secondary dementia caused by inflammatory diseases, infections, intoxication, metabolic diseases or tumors. ApoE genotypes were determined at the Gene Bank, Inc. (Seoul, Korea), using previously published standard procedures [10]. Informed written consent to participate was obtained from each subject and caregiver. This study was conducted in accordance with the Declaration of Helsinki and its subsequent revisions and approved by ethics committees at each center and the Korean Association for Geriatric Psychiatry.

\section{Efficacy Outcome Measures}

The primary efficacy outcome measure was the ADAS-cog/11 [9]. Secondary efficacy measures included the Clinician's Interview-Based Impression of Change plus Caregiver Input (CIBICplus) [11], the Disability Assessment for Dementia Scale (DAD) [12] and the Behavioural Pathology in Alzheimer's Disease Rating Scale (BEHAVE-AD) [13]. All efficacy variables were analyzed as a change from baseline, referring to the time when a subject was randomized and study drug dispensed.

The validity and reliability of the Korean versions of the ADAS$\operatorname{cog}$ [14], the CIBIC-plus [unpubl. data], the DAD [15] and the BEHAVE-AD $[16,17]$ used in this study have been confirmed in Korea. Joint rating sessions were held twice just before the study period. The intraclass correlation coefficients for inter-rater reliability were 0.89 for the ADAS-cog/11, 0.85 for the BEHAVE-AD, 0.93 for the DAD and 0.83 for the CIBIC-plus.

The CIBIC-plus provides a global impression of the patient's deterioration or improvement over the course of the trial. A trained clinician scored the CIBIC-plus, based on separate interviews with the patient and the caregiver(s). Scores ranged from 1 (markedly improved) through 4 (no change) to 7 (markedly worse). The 40item DAD is based on interviews with the caregiver and assesses basic ADL, instrumental ADL, leisure activities, initiation, planning and organization and effective performance with a score ranging from 0 to 100 . The 25-item BEHAVE-AD assesses behavioral disturbances exhibited by the patient during the prior 2-week interval, using information ascertained from caregivers who had been responsible for the care of the patient. Scores for each item range from 0 to 3, with higher scores indicating increased behavioral severity.

\section{Tolerability Outcome Measures}

The investigator or research assistant evaluated tolerability throughout the study using physical examinations, measurement of vital signs (including heart rate and blood pressure), chest radiography, 12-lead electrocardiography, standard laboratory tests (including hematology, blood chemistry and urinalysis) and monitoring for AEs. AEs were classified according to World Health Organization preferred terms and were recorded at every visit after randomization; the investigator noted the specific symptoms, time of occurrence, severity, treatment, outcome and the causal relationship of each AE to the trial drug.

\section{Statistical Analysis}

Demographic Variables

Univariate analyses were conducted to calculate descriptive statistics of all variables (either continuous or binary) and to test the normality of dependent variables. Baseline characteristics of two groups (a group with at least one $\varepsilon 4$ allele, $\varepsilon 4$ carriers, and a group 
without $\varepsilon 4$ allele, $\varepsilon 4$ noncarriers) were compared using one-way analyses of variance for continuous variables and the CochranMantel-Haenszel test for categorical variables.

Efficacy and Tolerability Analyses

To examine whether the effect of galantamine treatment was modified by the presence of the ApoE $\varepsilon 4$ allele, we applied the analysis of mixed model (for these dependent variables including the ADAS-cog/11, the DAD and the BEHAVE-AD) and the generalized estimating equations (GEEs) (for these dependent variables including the CIBIC-plus and the AEs) using the following independent variables: times of repeated assessment $(0,4,8$, or 16 weeks), dose ( $8 \mathrm{mg}, 16 \mathrm{mg}, 24 \mathrm{mg}$ ) and individual indicator (such as age and gender) to adjust individual variability as covariates. To control for the effect of different doses of galantamine given to the three arms, we include dose as a covariate in the mixed model and GEE analyses. Treatment by center interaction was tested and removed from the model as it was not significant at the 5\% level.

The same statistical analyses were applied to both the intent-totreat (ITT) group and the per-protocol (PP) group. The ITT analysis included subjects $(n=202)$ who were successfully enrolled in this study, agreed to ApoE genotyping and subsequently completed baseline evaluation. The PP analysis included subjects $(n=159)$ in the ITT group who completed all the assessment at baseline (week 0 ) and after 4, 8 and 16 weeks. Since the results of the ITT and the PP group did not differ, we present the more conservative result of ITT analyses.

\section{Results}

\section{Patient Population}

Of the 234 patients who entered the active arms of the study [5], 202 agreed to ApoE genotyping and gave written consents for this genetic study. There were no signifi- cant differences in the baseline characteristics between those who agreed to ApoE genotyping $(\mathrm{n}=202)$ and those who did not $(\mathrm{n}=32)$.

The number and frequency of each genotype was 15 (7.4\%) for $\varepsilon 2 / \varepsilon 2,7(3.5 \%)$ for $\varepsilon 2 / \varepsilon 3,5(2.5 \%)$ for $\varepsilon 2 / \varepsilon 4$, $65(32.2 \%)$ for $\varepsilon 3 / \varepsilon 3,65(32.2 \%)$ for $\varepsilon 3 / \varepsilon 4$ and $45(22.3 \%)$ for $\varepsilon 4 / \varepsilon 4$, respectively (table 1 ). There was no statistically significant difference in the frequency of ApoE genotype by gender $\left(\chi^{2}=0.12, p=0.73\right)$. The proportion of patients with at least one $\varepsilon 4$ allele ( $\varepsilon 4$ carriers; $\mathrm{n}=115$; $57 \%$ ) was higher than that of patients without $\varepsilon 4$ allele ( $\varepsilon 4$ noncarriers; $\mathrm{n}=87 ; 43 \%$ ). As shown in table 2 , the baseline demographic and medical characteristics were similar between $\varepsilon 4$ carriers and $\varepsilon 4$ noncarriers, and there were no statistically significant differences.

Table 1. ApoE genotype distribution in the study population

\begin{tabular}{lccr}
\hline $\begin{array}{l}\text { ApoE } \\
\text { genotype }\end{array}$ & $\begin{array}{l}\text { Males } \\
(\mathrm{n}=47)\end{array}$ & $\begin{array}{l}\text { Females } \\
(\mathrm{n}=155)\end{array}$ & $\begin{array}{l}\text { Total } \\
(\mathrm{n}=202)\end{array}$ \\
\hline$\varepsilon 2 / \varepsilon 2$ & $4(8.5)$ & $11(7.1)$ & $15(7.4)$ \\
$\varepsilon 2 / \varepsilon 3$ & $0(0.0)$ & $7(4.5)$ & $7(3.5)$ \\
$\varepsilon 2 / \varepsilon 4$ & $2(4.3)$ & $3(1.9)$ & $5(2.5)$ \\
$\varepsilon 3 / \varepsilon 3$ & $15(31.9)$ & $50(32.3)$ & $65(32.2)$ \\
$\varepsilon 3 / \varepsilon 4$ & $14(29.8)$ & $51(32.9)$ & $65(32.2)$ \\
$\varepsilon 4 / \varepsilon 4$ & $12(25.5)$ & $33(21.3)$ & $45(22.3)$
\end{tabular}

Numbers in parentheses represent percentages. There was no statistically significant difference in the frequency of ApoE genotype by gender $\left(\chi^{2}=0.12, p=0.73\right)$.

Table 2. Baseline demographic and clinical characteristics of the study population $(n=202)$

\begin{tabular}{|c|c|c|c|c|}
\hline \multirow[t]{2}{*}{ Characteristics } & \multirow[t]{2}{*}{ Total group } & \multicolumn{2}{|c|}{ Group by ApoE genotype } & \multirow[t]{2}{*}{$\mathrm{p}$ value } \\
\hline & & $\begin{array}{l}\varepsilon 4 \text { carriers } \\
(\mathrm{n}=115)\end{array}$ & $\begin{array}{l}\varepsilon 4 \text { noncarriers } \\
(\mathrm{n}=87)\end{array}$ & \\
\hline \multicolumn{5}{|l|}{ Demographic } \\
\hline Age, years & $74.8 \pm 7.5$ & $75.0 \pm 7.6$ & $74.4 \pm 7.4$ & 0.503 \\
\hline Males & $47(23 \%)$ & $28(24 \%)$ & $19(22 \%)$ & 0.676 \\
\hline Females & $155(77 \%)$ & $87(76 \%)$ & $68(78 \%)$ & \\
\hline \multicolumn{5}{|l|}{ Clinical } \\
\hline Duration of formal education, years & $5.4 \pm 4.4$ & $5.4 \pm 4.7$ & $5.3 \pm 4.1$ & 0.805 \\
\hline Time since diagnosis of cognitive abnormality, years & $3.1 \pm 2.0$ & $3.1 \pm 1.7$ & $3.2 \pm 2.4$ & 0.877 \\
\hline Total MMSE score & $16.4 \pm 3.3$ & $16.3 \pm 3.4$ & $16.7 \pm 3.2$ & 0.371 \\
\hline
\end{tabular}

Values are expressed as mean \pm standard deviation of mean unless otherwise indicated.

Data were analyzed between ApoE $\varepsilon 4$ carriers and ApoE $\varepsilon 4$ noncarriers by means of one-way analysis of variance, except for gender ( $\chi^{2}$ test). 
Fig. 1. Mean change (standard error) in ApoE $\varepsilon 4$ carriers and ApoE $\varepsilon 4$ noncarriers over time from baseline in behavioral symptoms (as assessed with the BEHAVE-AD). $F(1,183)$ means $F$ value for mixed model with numerator degree of freedom (i.e. 1) and denominator degree of freedom (i.e. 183) in parentheses.

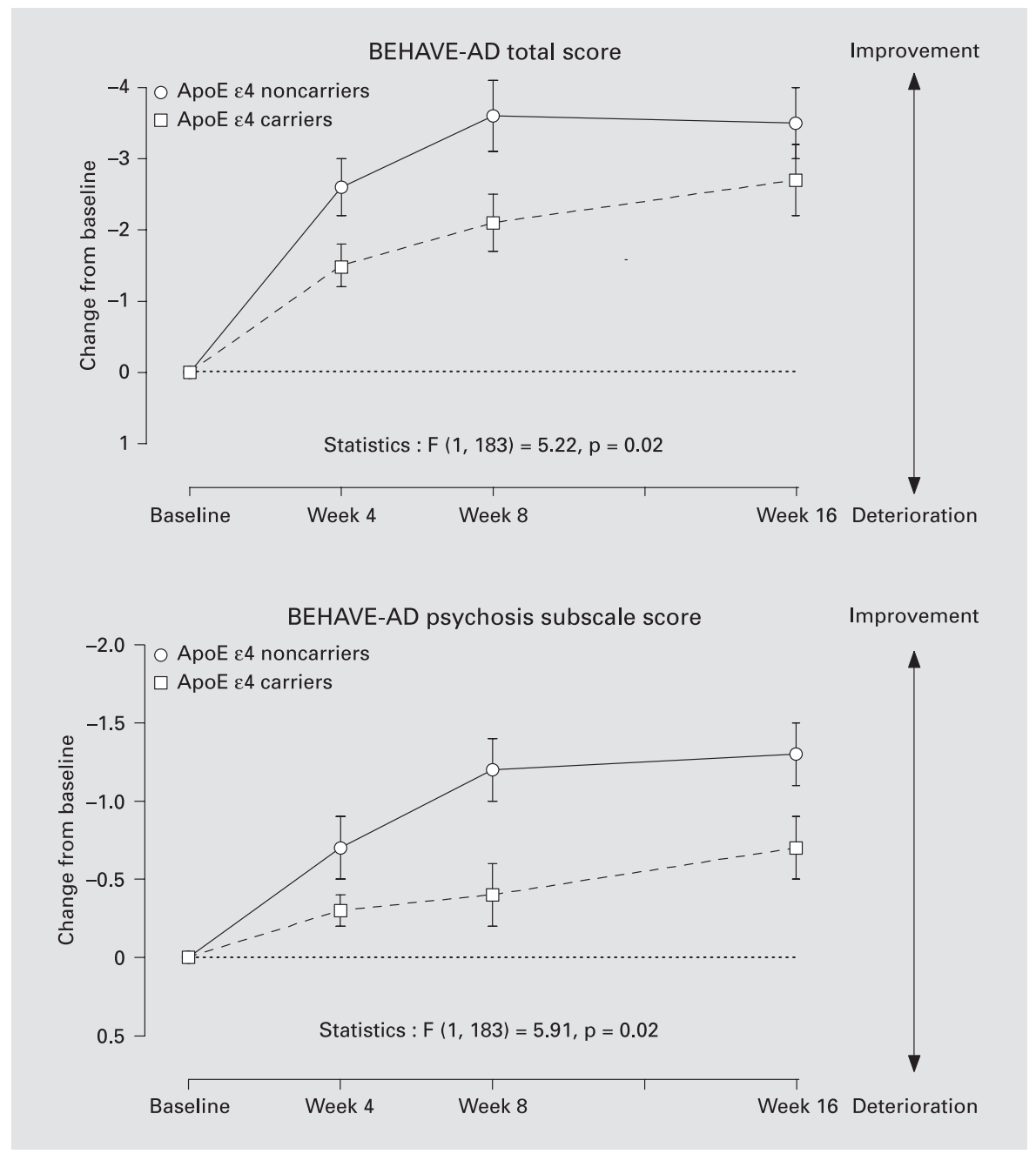

Effect of the ApoE $\varepsilon 4$ Allele on Changes in

Cognition, Global Rating, Behavior and Function in

\section{Galantamine Treatment}

Table 3 indicates the serial mean changes from baseline in outcome variables during the 16-week galantamine treatment for ApoE $\varepsilon 4$ carriers and $\mathrm{ApoE} \varepsilon 4$ noncarriers. Results of longitudinal analyses of the ADAS-cog/11-K, the CIBIC-plus-K, the DAD-K and the subscales of the DAD-K (basic ADLs, instrumental ADLs) showed improvement in cognition, global rating and function in both groups relative to baseline, and there were no statistically significant differences in these efficacy outcome variables between $\varepsilon 4$ carriers and $\varepsilon 4$ noncarriers. Proportions of the patients who scored $\leq 4$ on the CIBIC-plus-K were $62.1 \%$ for $\varepsilon 4$ carriers and $69.4 \%$ for $\varepsilon 4$ noncarriers. This difference was not statistically significant (GEEs: $\mathrm{p}=0.32$; table 3 )
Throughout the 16-week study period, both groups demonstrated improved mean total BEHAVE-AD-K score and mean psychosis subscale score compared with baseline (fig. 1). However, ApoE $\varepsilon 4$ noncarriers showed better improvement in mean total BEHAVE-AD-K score and mean psychosis (delusions and hallucinations) subscale score than ApoE $\varepsilon 4$ carriers (mixed model: both $\mathrm{p}=0.02$ ).

\section{Effect of the ApoE \&4 Allele on AEs in Galantamine Treatment}

The incidence of AEs was $37.2 \%$ in the ApoE $\varepsilon 4$ carriers and $31.0 \%$ in the ApoE $\varepsilon 4$ noncarriers. The most frequent AEs were dizziness, headache, nausea, headache, weight loss, loss of appetite and vomiting (table 4). There was no statically significant difference in AEs between the two groups except for weight loss. ApoE $\varepsilon 4$ carriers complained of weight loss more frequently [inci- 
Table 3. Comparison of effect of galantamine treatment on outcomes between ApoE $\varepsilon 4$ carriers and ApoE $\varepsilon 4$ noncarriers

\begin{tabular}{|c|c|c|c|c|c|c|c|}
\hline \multirow[t]{2}{*}{ Measurement } & \multicolumn{3}{|c|}{$\varepsilon 4$ carrier $(n=115)$} & \multicolumn{3}{|c|}{$\varepsilon 4$ noncarrier $(\mathrm{n}=87)$} & \multirow[t]{2}{*}{ Group difference $^{a}$} \\
\hline & $\begin{array}{l}\Delta(\text { week } 4- \\
\text { week 0) }\end{array}$ & $\begin{array}{l}\Delta(\text { week } 8- \\
\text { week 0) }\end{array}$ & $\begin{array}{l}\Delta(\text { week } 16- \\
\text { week } 0)\end{array}$ & $\begin{array}{l}\Delta(\text { week } 4 \text { - } \\
\text { week 0) }\end{array}$ & $\begin{array}{l}\Delta(\text { week } 8- \\
\text { week } 0)\end{array}$ & $\begin{array}{l}\Delta(\text { week } 16 \\
\text { - week 0) }\end{array}$ & \\
\hline ADAS-cog/11 b,c & $-2.3(0.4)$ & $-3.6(0.6)$ & $-4.3(0.6)$ & $-3.2(0.6)$ & $-4.9(0.7)$ & $-5.1(0.7)$ & $F(1,183)=1.95, p=0.16$ \\
\hline $\mathrm{DAD}^{\mathrm{b}, \mathrm{d}}$ & $2.6(0.9)$ & $3.7(1.2)$ & $3.8(1.5)$ & $4.0(1.6)$ & $5.0(1.7)$ & $3.4(1.6)$ & $F(1,183)=0.24, p=0.63$ \\
\hline Basic ADLs ${ }^{\mathrm{b}, \mathrm{d}}$ & $0.5(0.9)$ & $1.6(1.3)$ & $0.3(1.9)$ & $1.4(1.8)$ & $0.4(2.3)$ & $0.8(2.2)$ & $F(1,183)=0.01, p=0.99$ \\
\hline Instrumental ADLs ${ }^{\mathrm{b}, \mathrm{d}}$ & $4.8(1.5)$ & $5.3(1.7)$ & $6.7(2.0)$ & $6.0(2.0)$ & $9.0(2.0)$ & $5.9(2.1)$ & $F(1,183)=0.41, p=0.52$ \\
\hline CIBIC-plus $\leq 4$ & $47(43.9 \%)$ & $57(60.0 \%)$ & $54(62.1 \%)$ & $38(47.5 \%)$ & $51(68.9 \%)$ & $50(69.4 \%)$ & $\mathrm{Z}=-1.00 \quad \mathrm{p}=0.32$ \\
\hline
\end{tabular}

${ }^{a}$ Mixed model and GEEs were used to test statistical significance of change from baseline at 16 weeks between $\varepsilon 4$ carriers and $\varepsilon 4$ non-carriers. F $(1,183)$ means F value for the mixed model with numerator degree of freedom (i.e. 1) and denominator degree of freedom (i.e., 183) in parenthesis.

${ }^{\mathrm{b}}$ Values represent mean (standard error) change from baseline.

${ }^{c}$ Negative changes indicate improvement.

${ }^{\mathrm{d}}$ Positive changes indicate improvement.

dence $=9.6 \%(n=11)$, mean (standard deviation $)$ weight lost during 16 weeks $=2.8 \mathrm{~kg}(2.2)]$ than ApoE $\varepsilon 4$ noncarriers [incidence $=1.2 \%(\mathrm{n}=1), 4 \mathrm{~kg}$ weight loss in one case during 16 weeks] (GEEs: $\mathrm{p}=0.0003$ ). However, 92\% $(\mathrm{n}=11 / 12)$ of patients who complained weight loss completed this 16-week trial successfully.

\section{Discussion}

Based on longitudinal data analyses of 202 patients with mild to moderate $\mathrm{AD}$ in this 16-week, prospective, randomized, double-blind galantamine trial, we analyzed the effect of the ApoE $\varepsilon 4$ allele (i.e. ApoE $\varepsilon 4$ carriers versus ApoE $\varepsilon 4$ noncarriers) on change in the 4 outcome measures (ADAS-cog/11-K, CIBIC-plus-K, DAD-K and BEHAVE-AD-K) and incidence of AEs. Galantamine produced improvement in cognition, global rating, function and behavior regardless of whether the ApoE $\varepsilon 4$ allele was present or not. The ApoE genotype frequency distribution in this study was very similar to those reported in the SAB-INT-12, SAB-USA-25, GAL-INT-1 and GAL-INT-2 trials $(\varepsilon 2 / \varepsilon 2: 0.1 \%, \varepsilon 2 / \varepsilon 3: 4 \%, \varepsilon 2 / \varepsilon 4: 3 \%$, $\varepsilon 3 / \varepsilon 3: 31 \%, \varepsilon 3 / \varepsilon 4: 47 \%, \varepsilon 4 / \varepsilon 4: 16 \%$ ) [4]. As in the original study [5], irrespective of whether the ApoE $\varepsilon 4$ allele was present or absent, robust dose-response relationship between ADAS-cog/11-K and galantamine dosage was demonstrated when compared with baseline (mixed model: $\mathrm{p}=0.0052$ ). We observed two more significant findings. First, ApoE $\varepsilon 4$ noncarriers showed better improvement in mean psychosis (delusions and hallucinations) sub-
Table 4. Effect of ApoE $\varepsilon 4$ allele on AEs in galantamine treatment

\begin{tabular}{lllr}
\hline & \multicolumn{2}{l}{$\begin{array}{l}\text { Proportion experiencing } \\
\text { adverse events, } \%\end{array}$} & $\mathrm{p} \mathrm{value}$ \\
\cline { 2 - 3 } & $\begin{array}{l}\varepsilon 4 \text { carriers } \\
(\mathrm{n}=115)\end{array}$ & $\begin{array}{l}\mathrm{a} 4 \text { noncarriers } \\
(\mathrm{n}=87)\end{array}$ & \\
\hline All adverse events & 37.2 & 31.0 & 0.13 \\
Nausea & 11.1 & 8.1 & 0.21 \\
Vomiting & 4.4 & 3.5 & 0.61 \\
Dizziness & 14.8 & 11.5 & 0.26 \\
Headache & 12.2 & 6.9 & 0.06 \\
Weight loss & 9.6 & 1.2 & $<0.01$ \\
Loss of appetite & 5.2 & 8.1 & 0.15 \\
\hline
\end{tabular}

${ }^{a}$ Difference was tested by GEEs after controlling for the effect of galantamine dose $(\mathrm{p}<0.05)$.

scale score of the BEHAVE-AD-K than ApoE $\varepsilon 4$ carriers. Second, weight loss was significantly more incident in ApoE $\varepsilon 4$ carriers $(n=11 ; 9.6 \%)$ than in ApoE $\varepsilon 4$ noncarriers $(n=1 ; 1.2 \%)$ during the 16 -week treatment period.

There have been discrepant reports on the effect of ApoE genotype on clinical response to AChEI therapy. For example, Poirier et al. [2] reported that $60 \%$ of ApoE $\varepsilon 4$ carriers achieved ADAS-cog scores worse than baseline, whereas more than $80 \%$ of ApoE $\varepsilon 4$ noncarriers had improved ADAS-cog scores compared with baseline. Farlow et al. [18] reported that there were no differences in treatment response by genotype. MacGowan et al. [19] 
reported that ApoE genotype did not affect response to AChEI therapy in the short term, but it may affect it over a longer term (i.e. 12 months). Such variations may be attributable to different study designs (sample size, doses, outcome definition and length of trial) and pharmacokinetic and pharmacodynamic characteristics of the different AChEIs as well [4]. Four randomized, placebo-controlled trials of galantamine, donepezil and metrifonate with large samples reported that ApoE was not a good predictor of response in cognition measured by ADAScog or MMSE [4, 20-22]. Aerssens et al. [4] also collected data from 4 similarly designed, international, placebocontrolled, multi-center clinical trials to study the association of ApoE genotype with age at onset, rate of decline and responsiveness to therapy. The study included 1,528 subjects diagnosed with probable $\mathrm{AD}$ who had undergone 3-12 months of treatment with galantamine or sabeluzole. The efficacy outcomes were measured by mean change from baseline in total ADAS-cog score and mean change from baseline in total DAD score. The proportion of ApoE $\varepsilon 4$ noncarriers was 35\%. There was no association between ApoE genotype and response to treatment measured by the ADAS-cog and DAD [21]. Our study is comparable to previous 4 studies included in the report by Aerssens et al. in several ways: (1) the same efficacy outcome measure; (2) similar proportion of $\varepsilon 4$ noncarriers (35 vs. $43 \%$ ) and (3) no association between ApoE genotype and change in cognition and function as a response to galantamine treatment.

In addition, to our knowledge, this may be the first report of the differential effect of ApoE genotype (ApoE $\varepsilon 4$ carriers vs ApoE $\varepsilon 4$ noncarriers) on psychotic symptoms (delusions and hallucinations) and AE (weight loss) in galantamine treatment of patients with $\mathrm{AD}$. Consistent with other drug-related AEs reported in this study, weight loss itself was so mild and transient (mean weight reduction $=2.8 \mathrm{~kg})$ that $92 \%(\mathrm{n}=11 / 12)$ of patients who complained of weight loss completed this 16-week trial successfully. There has been no report on the effect of ApoE genotype on behavioral and psychological symptoms of dementia (BPSD) and AEs in the AChEI treatment of patients with AD. In their cross-sectional study, Harwood et al. [23] reported elevated risk for psychosis among ApoE $\varepsilon 4$ carriers in 501 patients with $\mathrm{AD}$, specifically at the severe stage of cognitive impairment after controlling for the effects of age, gender, education and level of cognitive impairment. In their 1-year observational pilot study $(n=51)$, Ballard et al. [24] found that all of their $28 \mathrm{AD}$ patients with one or more $\varepsilon 4$ alleles experienced psychotic symptoms, suggesting that AD patients with
ApoE $\varepsilon 4$ genotype were significantly more likely to experience psychosis. These two reports had not dealt with use of drug, especially AChEIs, but showed ApoE genotyperelated difference in incidence of psychosis in patients with AD. Taken together, the results of this study and studies by Harwood et al. [23] and Ballard et al. [24] provide evidence for the role of the ApoE genotype as a biological marker for subgroups of AD based on clinical presentation. The ApoE $\varepsilon 4$ allele has been linked with increased neuritic plaques and cerebral amyloid angiopathy [25], greater atrophy in medial temporal areas [26] and more profound cholinergic loss in the frontal cortex [27]. Zubenko et al. [28] found that the ApoE $\varepsilon 4$ allele frequency in AD patients with psychotic features was nearly four times that detected in patients without psychotic features. However, there have been some other equivocal reports on ApoE $\varepsilon 4$ and psychosis [28, 29].

It is well recognized that different patients respond in different ways to the same medication. These differences are often greater among members of a population than within the same person at different times or between monozytotic twins [30]. Although many nongenetic factors influence the effects of medications, including age, organ function, concomitant therapy, drug interaction and the nature of the disease, there are now numerous examples of cases in which interindividual differences in drug response are due to sequence variants in genes encoding drug-metabolizing enzymes, drug transporters, or drug targets [31].

Three important issues must be considered with regard to our study. (1) BPSD occurs in nearly all patients with AD. Although BPSD is originally derived from deteriorated brain function, BPSD is usually triggered by environmental stimuli and can be relieved by nonpharmacological measures. Future studies will further clarify the underlying mechanism of differential frequency of psychotic symptoms in $\mathrm{AD}$ by presence or absence of the ApoE $\varepsilon 4$ allele, including effects of the drug, especially AChEIs. (2) This study is not a placebo-controlled study. Its aims were to investigate the effect of the ApoE $\varepsilon 4$ allele on galantamine treatment, not to compare active arms with a placebo group. However, efficacy measurements were compared with baseline, and the effect sizes are comparable to those detected in previous placebo-controlled studies of galantamine [4], suggesting that the results of this study are in line with the general efficacy of galantamine in other $\mathrm{AD}$ populations. (3) The study is not sufficiently large to provide adequate power to detect the gene-dose effect of the ApoE $\varepsilon 4$ allele on the efficacy and tolerability of galantamine. 


\section{Acknowledgments}

This study was supported by funding from Janssen Korea, Seoul, Korea. The authors acknowledge the study investigators and staff at each center as well as the participating patients and caregivers.

In addition to the authors, the following were members of the Korean Galantamine Study Group: Byeong Kil Yeon, Department of Psychiatry, Hallym University College of Medicine, Seoul, Korea; Jong Han Park, Department of Psychiatry, The Catholic University of Daegu School of Medicine, Daegu, Korea; Jung Ho Lee, Department of Neuropsychiatry, Inje University School of Medicine, Seoul, Korea; Jae Nam Bae, Department of Psychiatry, InHa University College of Medicine, Incheon, Korea; Han-Yong Jung, Soonchunhyang University College of Medicine, Bucheon, Korea.

\section{References}

$\checkmark 1$ Corder EH, Saunders AM, Strittmatter WJ, Schmechel DE, Gaskell PC, Small GW, Roses AD, Haines JL, Periack-Vance MA: Gene dose of apolipoprotein E type 4 allele and the risk of Alzheimer's disease in late onset families. Science 1993;261:921-923.

$\checkmark 2$ Poirier J, Delisle MC, Quirion R, Aubert I, Farlow M, Lahiri D, Hui S, Bertrand P, Nalbantoglu J, Gilfix BM, et al: Apolipoprotein E4 allele as a predictor of cholinergic deficits and treatment outcome in Alzheimer disease. Proc Natl Acad Sci USA 1995;92:12260-12264.

3 Orgogozo: Treatment of Alzheimer's disease with cholinesterase inhibitors. An update on currently used drugs; in Iqbal K, Winblad B (eds): Alzheimer's Disease and Related Disorders: Research Advances. Bucharest, Ana Aslan International Academy of Aging, 2003, pp 663-675.

4 Aerssens J, Raeymaekers P, Lilienfeld S, Geerts H, Konings F, Parys W: ApoE genotype: no influence on galantamine treatment efficacy nor on rate of decline in Alzheimer's disease. Dement Geriatr Cogn Disord 2001;12:69-77.

$\checkmark 5$ Suh GH, Jung HY, Lee CU, et al: A prospective, double-blind, community-controlled comparison of three doses of galantamine in the treatment of mild to moderate Alzheimer's disease in a Korean population. Clin Ther 2004;26:1608-1618.

6 American Psychiatric Association: Diagnostic and Statistical Manual of Mental Disorders, ed 4. Washington, American Psychiatric Association, 1994.

7 McKhann G, Drachman D, Folstein M, Katzman R, Price D, Stadlan EM: Clinical diagnosis of Alzheimer's disease: report of the NINCDS-ADRDA Work Group under the auspices of Department of Health and Human Services Task Force on Alzheimer's Disease. Neurology 1984;34:939-944.

-8 Folstein MF, Folstein SE, McHugh PR: 'Minimental state': a practical method for grading the cognitive state of patients for the clinician. J Psychiatr Res 1975;12:189-198.

$\checkmark 9$ Rosen WG, Mohs RC, Davis KL: A new rating scale for Alzheimer's disease. Am J Psychiatry 1984; 141:1356-1364.

10 Hixson JE, Vernier DT: Restriction isotyping of human ApoE by gene amplification and cleavage with Hba. J Lipid Res 1990;31:545548 .
1 Schneider LS, Olin JT, Doody RS, Clark CM, Morris JC, Reisberg B, et al: Validity and reliability of the Alzheimer's Disease Cooperative Study-Clinical Global Impression of Change. The Alzheimer's Disease Cooperative Study. Alzheimer Dis Assoc Disord 1997;11:S22S32.

12 Gélinas I, Gauthier L, McIntyre M, Gauthier $\mathrm{S}$ : Development of a functional measure for persons with Alzheimer's disease: the Disability Assessment for Dementia. Am J Occup Ther 1999;53:471-481.

13 Reisberg B, Borensteen J, Sabbs S, Ferris S, Franssen E, Georgotas A: Behavioural symptoms in Alzheimer's disease: phenomenology and treatment. J Clin Psychiatry 1987;48(suppl):9-15.

14 Suh GH, Mohs R: Validation of the Korean version of the Alzheimer's Disease Assessment Scale. J Korean Geriatr Soc 2003;7:267-277.

15 Suh GH: Validation of the Korean version of the Disability Assessment in Dementia Scale. J Korean Geriatr Soc 2003; 7:278-287.

16 Suh GH, Son HG, Shin H, Kim IM, Hong S, Park JH, Choi IG, Kim SK, Yeon BK: Reliability and analysis of symptom category scores of the Behavior Pathology in Alzheimer's disease Rating Scale, Korean version (BEHAVEAD-K). J Korean Geriatr Psychiatry 2001;5: 50-57.

17 Suh GH, Park JH: The Behavior Pathology in Alzheimer's disease Rating Scale, Korean version (BEHAVE-AD-K): factor structure among Alzheimer's disease inpatients. J Korean Geriatr Psychiatry 2001;5:86-95.

18 Farlow MR, Lahiri DK, Poirier J, Davignon J, Schneider L, Hui SL: Treatment outcome of tacrine therapy depends on apolipoprotein genotype and gender of the subjects with Alzheimer's disease. Neurology 1998;50:669677.

19 MacGowan SH, Wilcock GK, Scott M: Effect of gender and apolipoprotein E genotype on response to anticholinesterase therapy in $\mathrm{Alz}$ heimer's disease. Int J Geriatr Psychiatry 1998; 13:625-630.

20 Wilcock GK, Lilienfeld S, Gaens E: Efficacy and tolerability of galantamine in patients with mild to moderate Alzheimer's disease: multicentre randomized controlled trial. Galantamine International-1 Study Group. BMJ 2000;321:1445-1449.
21 Winblad B, Engedal K, Soininen H, Verhey F, Waldemar G, Wimo A, et al: A 1-year, randomized, placebo-controlled study of donepezil in patients with mild to moderate AD. Neurology 2001;57:489-495.

22 Farlow MR, Cyrus PA, Nadel A, Lahiri DK, Brashear A, Gulanski B: Metrifonate treatment of AD: influence of ApoE genotype. Neurology 1999;53:2010-2016.

23 Harwood DG, Barker WW, Ownby RL, George-Hyslop PS, Duara R: ApolipoproteinE (Apo-E) genotype and symptoms of psychosis in Alzheimer's disease. Am J Geriatr Psychiatry 1999; 7:119-123.

24 Ballard C, Massey H, Lamb H, Morris C: Apolipoprotein E: Non-cognitive symptoms and cognitive decline in late onset Alzheimer's disease. J Neurol Neurosurg Psychiatry 1997;3: 273-274.

25 Olichney JM, Hansen LA, Galasko D, et al: The apolipoprotein E $\varepsilon 4$ allele is associated with increased neuritic plaques and cerebral anyloid angiopathy in Alzheimer's disease and Lewy-body variant. Neurology 1996;47:190_ 196.

26 Lehtovirta M, Soininen H, Laakso MP, et al: SPECT and MRI analysis in Alzheimer's disease: relation to apolipoprotein $\mathrm{E} \varepsilon 4$ allele. $\mathrm{J}$ Neurol Neurosurg Psychiatry 1996;60:640649.

27 Soininen H, Kosumen O, Helisami S, et al: A severe loss of choline acetyltransferase in the frontal cortex of Alzheimer's patients carrying apolipoprotein $\varepsilon 4$. Neurosci Lett 1995; 187 : 79-82.

28 Zubenko GS, Henderson R, Stiffler JS, Stabler S, Rosen J, Kaplan BB: Association of the ApoE $\varepsilon 4$ allele with clinical subtypes of late life depression. Biol Psychiatry 1996;40:10081016.

29 Cacabelos R, Rodriguez B, Carrera C, Beyer K, Lao JI, Sellers MA: Behavioral changes associated with different apolipoprotein E genotypes in dementia. Alzheimer Dis Assoc Disord 1997;11(suppl 4):S27-S34.

30 Vesell ES: Pharmacogenetic perspectives gained from twin and family studies. Pharmacol Ther 1989;41:535-552.

31 Evans WE, Johnson JA: Pharmacogenomics: the inherited basis for interindividual differences in drug response. Annu Rev Genomics Hum Genet 2001;2:9-39. 